\title{
A influência do design emocional em projetos de artefatos inclusivos para autistas - Estudo de caso: Squease Vest
}

Emotional design and its influence on designing inclusive devices for autistic individuals - Case study: Squease Vest

FEITOSA, Marina Araújo F; Graduanda em Design; Universidade Federal de Pernambuco marina.affeitosa@hotmail.com

FIGUEIRÔA, Carolina F; Graduanda em Design; Universidade Federal de Pernambuco

carolffigueiroa@gmail.com

NAGAI, Luana; Graduanda em Design; Universidade Federal de Pernambuco

nagailuana@gmail.com

\section{Resumo}

Este artigo apresenta um estudo sobre o impacto do design emocional no projeto de artefatos para pessoas dentro do espectro autista. Uma análise experimental dos atributos do colete Squease Vest permitiu notar que seu desenho busca apresentar, à parte dos atributos físicos e mercadológicos, sensibilidade e cuidado com o usuário. Isso acabou levando a uma investigação acerca dos atributos psicológicos do design e como poderiam ter impactado na avaliação positiva do colete. Com isso, confirmou-se a importância de elaborar projetos de artefatos para pessoas com autismo unindo princípios de design universal e acessibilidade ao design emocional.

Palavras Chave: design emocional; autismo; artefatos inclusivos.

\section{Abstract}

This article presents a study on the impact of emotional design on designing devices for people in the autistic spectrum. An experimental analysis of the Squease Vest made it possible to notice its design aims to bear, apart from material attributes, sensitivity and a caring look towards the user, what made it stand out from other products. This led to an investigation about the psychologic attributes of design and how they might have added up on the positive evaluation of the vest. Thereby, the importance of designing for autistic people considering both universal design/accessibility and emotional design principles was confirmed.

Keywords: emotional design; autism; inclusive devices. 


\section{Introdução aos conceitos de design universal e design emocional}

Segundo Francisco e Menezes (2011), é importante compreender que o design universal é conhecido como a intervenção sobre espaços, produtos e serviços com a finalidade de permitir a todos o acesso equitativo, independente de gênero, idade, capacidade e nível cultural. Partindo desse princípio, segundo "The Principles of Universal Design" $(1997)^{1}$, o design universal se constitui dos seguintes princípios básicos: equiparação nas possibilidades de uso, flexibilidade no uso, uso simples e intuitivo, captação da informação, tolerância ao erro, dimensão e espaço para o uso e interação. Levando em conta o fato que os usuários também podem ter algum tipo de dificuldade na utilização de produtos ou ambientes, devido a características específicas do ambiente onde se encontram, o design universal aborda, além de características antropométricas e ergonômicas, deficiências sensório-motoras, condições do ambiente externo ou interno, características operacionais e limitações temporárias. Embasado nesses princípios, torna-se determinante no processo de projetar e atender simultaneamente ao maior número de pessoas de forma autônoma, segura e confortável.

Já se alinhando às abordagens metodológicas centradas no usuário, o campo do design emocional emergiu por volta da década de 1990. Seu objetivo é facilmente confundido, como se o designer pudesse projetar emoções: alegria, satisfação, calma. Na verdade, segundo Tonetto e Da Costa (2011), o objetivo dessa vertente é trazer um olhar detalhado para as experiências de caráter subjetivo, inerentes aos seres humanos, apoiando-se principalmente na psicologia, com a intenção de fornecer ferramentas e conhecimentos para projetos que têm o intuito de evitar ou despertar determinadas emoções. De acordo com Nielsen (2008), segregação e estigmatização são termos ainda pouco destacados na hora de se projetar para pessoas com deficiência, o que revela um problema básico: raramente o designer será usuário do próprio projeto. Nesse sentido, são comuns os projetos de design universal ou acessível em que se ignoram os aspectos sociológicos e emocionais daqueles usuários que deveriam ser seu foco. No caso de projetos de que preveem o uso por pessoas com atrasos no desenvolvimento ou dentro do espectro autista, se espera que o artefato englobe, também, questões cognitivas e psicológicas, e essa é uma barreira difícil de transpor quando o designer não faz parte do grupo para o qual está trabalhando.

Nesta mesma linha, ressalta Silva (2011) que, ao adequar produtos para pessoas com necessidades especiais, o designer está projetando para os demais usuários, pois um produto ou equipamento estudado para um indivíduo de capacidade limitada, seja a que nível for, pode ser, na maioria das vezes, facilmente manuseado por outro que não tenha essas limitações. Assim, se pode criar artefatos com maior alcance a uma variada gama de usuários e contribuir para a inclusão social destes.

Silva (2011) também escreve que, se tratando especificamente de usuários dentro do espectro autista, há um conjunto de obstáculos no desenvolvimento, compreensão e aprendizagem. Pessoas com autismo têm dificuldade em se expressar e comunicar-se com os outros e com o meio, o que implica na dificuldade em demais aprendizagens do dia-a-dia que requerem interação e envolvimento social. Além de haver variações nos níveis de habilidade cognitiva, também há condições de hiper ou hipossensibilidade a estímulos externos e ambientais, que podem afetar a realização de tarefas simples.

\footnotetext{
${ }^{1}$ Disponível em: http://universaldesign.ie/What-is-Universal-Design/The-7-Principles/
} 
Pesquisas que correlacionam o design de produto com o desenvolvimento e aprendizagem de crianças dentro do espectro autista são quase inexistentes. Há estudos específicos dentro do design de interface que tentam suprir essa relação entre usuário e designer, um já conhecido problema dentro do fazer design; porém, o que fazer quando o usuário apresenta uma condição que interfere em sua cognição, dificultando associações, abstrações e a leitura de símbolos ou ícones? A resposta para esse questionamento pode estar no design emocional.

Um exemplo de artefato com preocupação que se estende para além do funcionalismo, buscando abarcar o usuário em seus níveis de necessidade emocional e psicológica é a Máquina do Abraço, criada por Temple Grandin. Autista, inventora, designer e professora de ciência animal na Colorado State University, aos 18 anos Grandin criou a Squeeze Machine para aliviar seus ataques de pânico e ansiedade, e foi com o suporte da máquina, seus pais e profissionais em acompanhamento que aprendeu a lidar com a hipersensibilidade, possibilitando que interagisse melhor com outras pessoas e, mais tarde, tenha se tornado uma porta-voz mundial que mudou a maneira como o público percebe o autismo. Através da Máquina e das próprias experiências, verificou que a pressão de toque profundo, já amplamente estudada na medicina, afeta positivamente pessoas com autismo, acalmando-as.

Figura 1 - Máquina do Abraço
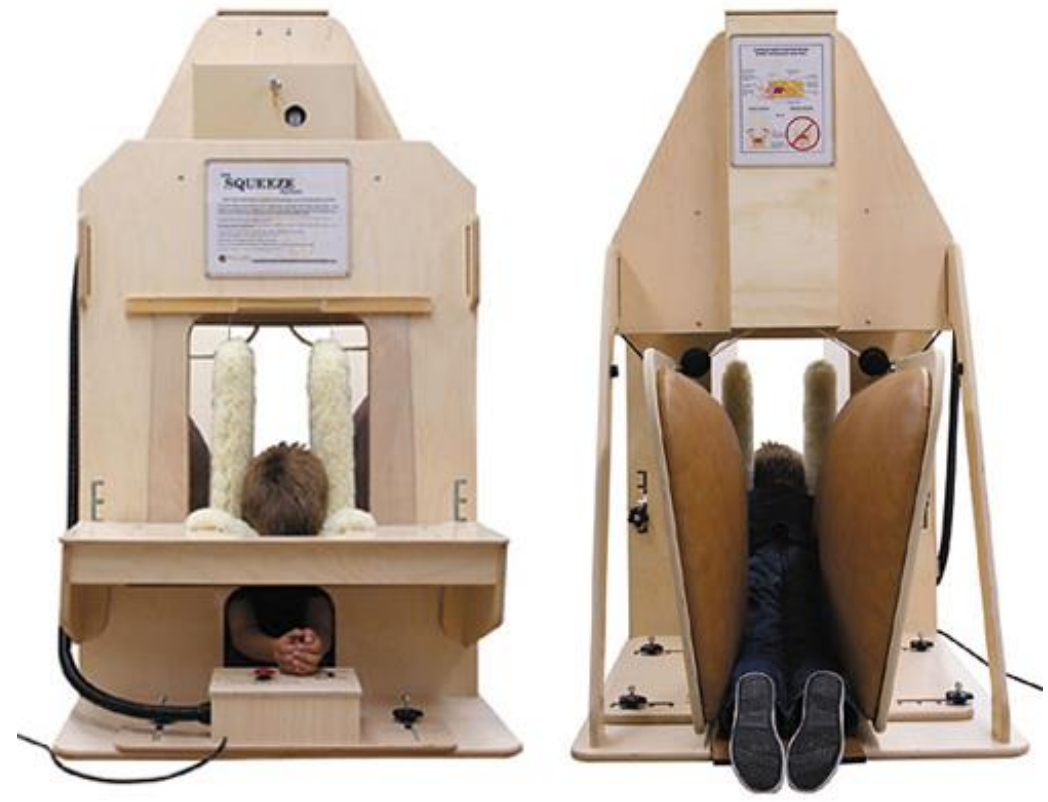

Fonte: squeasewear.com/en/portfolio-items/temple-grandin/ (2017)

\section{O colete Squease Vest}

Quase duas décadas depois da criação da Máquina do Abraço, em 2008, foi registrada a patente do Squease Vest, um colete com mecanismo que permite ao usuário controlar a pressão exercida em seu corpo através de um sistema de bombeamento de ar. Criado em Londres, como trabalho de conclusão de curso de quatro alunos do Royal College of Art and Design, teve como propulsor o fato de que um dos membros da equipe tem um sobrinho com autismo. Isso estimulou o grupo a se aproximar e olhar cuidadosamente para os usuários, significando que a empatia e cuidado estavam presentes desde o início do projeto. Ao desenvolver os estudos, aprenderam que 
pessoas com autismo lidam de forma positiva com pressão firme, parecida com um abraço, apesar das possíveis e eventuais dificuldades para engajar-se em contato físico. No website da marca, a Máquina do Abraço é apontada como referência pelos criadores.

Squease Vest tem o diferencial de trazer um conceito de mobilidade inédito ao projeto de Grandin: o usuário pode vestir o colete sob outras peças de roupa, pois seu perfil esbelto e peso reduzido não causam incômodos, permitindo que circule sem dificuldade por qualquer ambiente. Um aparelho robusto, pesado e que ocupa grande área foi, então, substituído por um item de vestuário facilmente dobrável e lavável.

Figura 2 - Componentes do Squease Vest

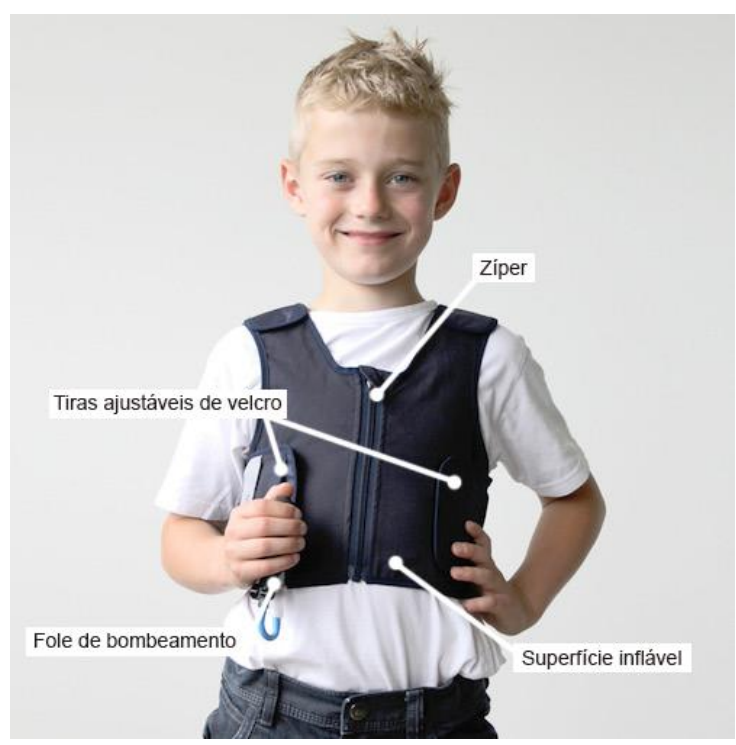

Fonte: adaptado de Squease Wear $^{2}$ (2017)

Através de análise baseada em Nakayama (2016) e "The Principles of Universal Design" (1997), foi percebido que Squease Vest se diferencia de outras tecnologias assistivas ou projetos de design universal ao atender tanto às questões utilitárias como àquelas relativas ao bem-estar. Além dos benefícios fisiológicos listados, o colete permite à pessoa com autismo ou Transtorno de Déficit de Atenção e Hiperatividade (TDAH) que retorne a uma condição de tranquilidade de forma autônoma, não a estigmatizando e incentivando a criação de mecanismos próprios para lidar com crises de sobrecarga sensorial ou postura defensiva tátil, sintomas comumente apresentados em ambos os casos. O projeto apresenta uma preocupação que vai além do funcionalismo (a roupa enquanto mero abrigo do corpo ao exterior): faz, também, provisões quanto à segurança psicológica do usuário.

Tal preocupação com a dimensão psicológica do design pode ser encontrada na literatura sobre design emocional, termo criado por Donald Norman no início do século XX. Na época, se discutia especialmente a relevância e convergência dos sentidos e da memória na criação de uma experiência usuário-produto, anterior à cognição propriamente dita. Ao projetar para com usuários com autismo, é de suma importância que isso seja levado em conta, visto que, dentro do espectro,

\footnotetext{
${ }^{2}$ Disponível em: https://www.squeasewear.com/about/product-features/
} 
apesar de haver variações nos níveis de habilidade cognitiva, também há condições em que se registra aumentada ou reduzida sensibilidade a estímulo do meio externo.

Ao analisar Squease Vest, percebeu-se que o artefato acaba incorporando princípios do design emocional, como a "estética da interação", que, segundo Overbeeke \& Wensveen (2003), prevê que a experiência funcional pura e simples não é suficiente. Trata-se de um conceito estético com foco no aspecto tátil e cinestésico, onde o usuário faz uma projeção da sensação de bem-estar causada pela interação com um objeto. Isso significa que, após o uso do Squease Vest, uma pessoa com autismo deve passar a registrar a sensação de estar acolhida, proporcionada pela pressão de toque profundo. Isso lhe será útil em um eventual momento de sobrecarga emocional, por exemplo, permitindo que desenvolva mecanismos próprios para lidar com esse tipo de situação sem a necessidade de contato com outro indivíduo.

Além disso, o colete demonstrou, para pessoas dentro do espectro autista, potencial no cumprimento dos três níveis de experiência propostos por Hekkert (2006): estético, cognitivo e emocional, estando os dois primeiros intimamente relacionados à satisfatória realização do último.

\section{Metodologia}

O método aplicado neste trabalho foi uma versão experimental de estudo de caso, que teve como objeto o Squease Vest, vestimenta destinada a indivíduos com autismo, TDAH e distúrbios sensoriais, que se destacou dentre outros artefatos inclusivos analisados por apresentar distinto cuidado com a segurança psicológica do usuário. A intenção dessa abordagem foi focar nas estratégias projetuais que nortearam a criação do colete, avaliando conceitualmente em qual medida aspectos do design emocional podem ter impactado atributos do produto.

Segundo Yin (2001), os estudos de caso representam, em geral, a estratégia preferida quando se questiona "como" e "por quê", e quando o pesquisador tem pouco controle sobre os eventos, por exemplo. O foco é que se explore a natureza da experiência enquanto fenômeno, no caso, a relação potencial entre os aspectos emocionais, a autonomia, o conforto e o usuário.

As ferramentas de análise tomadas como base para estudo foram duas fichas avaliativas, também em caráter experimental: uma voltada para a percepção do usuário final, adaptada de "The Principles of Universal Design" e outra, adaptação de Nakayama (2016). Ambas podem ser acessadas na seção "Apêndice". Objetivou-se verificar se se constituem satisfatórias na tarefa de observar um produto sob diversos ângulos, desde sua materialidade aos requisitos simbólicos e/ou mercadológicos.

Foram feitas pesquisas sobre o artefato através de websites e textos acadêmicos; as fichas de avaliação foram preenchidas pelas autoras separadamente e, em seguida, foi feito debate sobre todos os tópicos da análise, de forma a entrar em consenso e finalizar a avaliação do produto com comentários por tópicos, discutidos em detalhe no subcapítulo a seguir.

\subsection{Resultados}

O uso do Squease Vest aparentou ser eficaz na tentativa de trazer a sensação de acolhimento que uma pessoa dentro do espectro autista pode ter dificuldade de buscar através do contato físico com outro ser humano, e isso contribui para que se sinta bem realizando outras tarefas. Isso significa que, para além de realizar as funções e cumprir requisitos de materialidade de uma peça de roupa, o colete visa permitir ao usuário se beneficiar de segurança e autonomia baseadas na boa resposta 
à pressão de toque profundo.

Percebeu-se, também, que o artefato aparenta cumprir três princípios projetuais de design enunciados por Norman (1997): visceral, comportamental e reflexivo. No quesito visceral, que apelam diretamente aos sentidos: é feita de material leve e flexível, que com boa interação tátil; apresenta opções de escolha de modelos e cores diferentes; em nível comportamental, o mecanismo inflável vai além dessa primeira esfera, trazendo os benefícios da pressão de toque profundo, acalmando e auxiliando a lidar com a condição de hipo ou hipersensibilidade ao meio; não há complexidades cognitivas que dificultem o uso, já que se trata de um item de vestuário e está dentro das expectativas que usuário tem em relação a esse tipo de peça, reforçando sua fixação no nível reflexivo.

\subsubsection{Caracterização do artefato}

$\mathrm{Na}$ caracterização do artefato, estão os requisitos norteadores. São as necessidades mercadológicas e simbólicas, a autonomia, sensibilidade e respeito do ritmo corporal que o artefato garante ao usuário e suas considerações sobre tecnologias assistivas. O objeto de estudo dá indícios de que atende às necessidades mercadológicas, ao se direcionar para um público com necessidades específicas, provendo conforto e trazendo um valor simbólico importante de segurança e acolhimento.

O uso é adaptável, porém não flexível, visto que se trata de uma vestimenta, que só pode ser usada de uma forma; pode-se considerar que não promove segregação, permitindo, inclusive, que o usuário se aproxime de condições ideais e se sinta acolhido para realizar atividades rotineiras durante crises de ansiedade ou sobrecarga sensorial. O ritmo é controlado pelo próprio usuário e Squease Vest foi considerado sensível às necessidades dele.

\subsubsection{Requisitos gerais}

Estão relacionados à adequação, clareza e facilidade no uso do artefato e sua desenvoltura quanto à otimização da tarefa primordial. Nesse sentido, o Squease Vest aparenta cumprir em grande medida a potencial tarefa de trazer conforto, segurança e acolhimento ao usuário, permitindo que ele realize tarefas cotidianas com mais tranquilidade. No manual, encoraja-se que o usuário faça testes com o fole e se familiarize com os níveis de bombeamento e pressão.

Sheraz Arif, um dos criadores, afirmou que recebeu depoimentos de mães reconhecendo as realizações de seus filhos ao usar o colete; foram apontadas melhorias no sono e desenvolvimento de tarefas simples, como alimentação (Hillner, 2013). O desenho é simples e intuitivo, aliando um sistema de fole de bombeamento ao colete, que permite que o usuário controle o fluxo de enchimento do mesmo. A tarefa é clara, eliminando complexidades, exigindo para seu uso apenas o sentido do tato.

\subsubsection{Requisitos dos materiais}

Estão relacionados aos insumos do produto e maneira como foram aplicadas no artefato, bem como sua garantia de conforto relacionado à temperatura, peso, flexibilidade, além da segurança e manutenção do produto. O colete é anunciado como sendo leve, especialmente se comparado a outras tecnologias com propósito similar. Por se tratar de uma roupa inflável, não constitui um peso extra sobre o corpo. Os materiais de que é feito são flexíveis (possui elásticos e tiras de velcro para ajuste) e laváveis. Há pequenos orifícios distribuídos por toda sua extensão, permitindo livre ventilação e transpiração. 


\subsubsection{Requisitos de uso}

Dizem respeito à mobilidade que o artefato permite ao usuário durante seu uso, bem como ajustes e esforços necessários para uso do próprio artefato. $O$ fole que se aperta para inflar o colete está ao alcance da mão, podendo ser guardado para dentro do bolso frontal do modelo de moletom com capuz; não apresenta flexibilidade de uso, apesar de ser apresentado em diversos tamanhos, desde XXS e XS para crianças até modelos para adultos. As tiras de velcro permitem que seja adaptado para cada usuário. Permite que o usuário circule livremente e realize outras tarefas paralelas ao uso do colete.

Além disso, o manual instrui diversos padrões de aplicação de pressão, a depender das necessidades particulares do usuário. Pessoas que respondem mais intensamente à pressão de toque profundo são orientadas a iniciar com baixos níveis, aumentando-os gradativamente; àquelas que respondem melhor a altas pressões, recomenda-se inflar e esvaziar o colete intensamente seguidas vezes, deixando-o vazio por fim (Duvall, 2017).

\subsubsection{Requisitos avaliativos}

Se referem ao conforto global do objeto, ao aspecto estético-simbólico e à assimilação e facilidade de uso do artefato. Quanto a esses pontos, apenas o moletom com capuz apresenta mais opções de cores, havendo dois modelos de colete. O caráter visual acaba caindo para segundo plano ao se considerar que há gratificação ao sentido do tato, conferida pelo sistema de bombeamento.

Os modelos são discretos, esbeltos, não interferindo no aspecto geral da roupa do usuário e aumentando seu conforto ao prover sensação de acolhimento. No manual, o usuário é encorajado a se familiarizar com o fole e os níveis de pressão proporcionados, conferindo um sentido de controle anterior ao uso efetivo.

\subsubsection{Requisitos finais do produto}

Concluem a avaliação, levando em conta manutenção, clareza das informações do artefato e seu papel na otimização processual. Dessa forma, observa-se que o artefato é lavável e aparenta ser feito de materiais duráveis. Suas informações de uso são consideradas claras, otimizando a tarefa principal. De modo geral, Squease Vest foi entendido como um artefato bem-sucedido naquilo a que se propõe. O preço do colete em si parte de $£ 154$ (aproximadamente, $\mathrm{R} \$ 695$ ), podendo ser adquirido separadamente um moletom com capuz para alojá-lo por $£ 41$ (R\$185, em média).

A crescente demanda por artefatos inclusivos para pessoas com autismo contribuiu para incentivar os esforços de aumentar o alcance da distribuição do colete (Hillner, 2013). Assim, foi desenvolvido um sistema que permite aluga-lo por curtos períodos, e, caso seja adquirido posteriormente, abater o preço pago pelos aluguéis. 
Figura 3 - Modelo de moletom com capuz

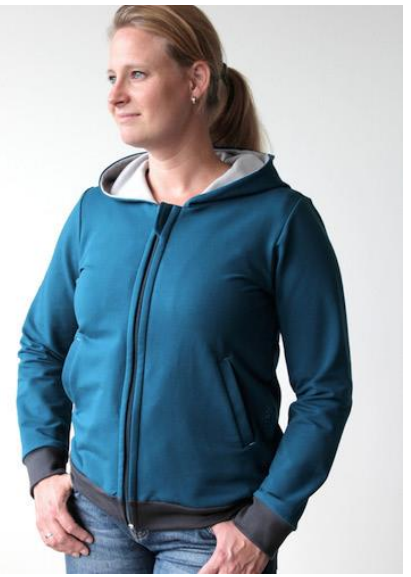

Fonte: adaptado de Squease Wear ${ }^{3}$ (2017)

\section{Conclusão}

Diante de uma realidade na qual o funcionalismo impera no design, nota-se uma grande dificuldade em abarcar as características psico-emocionais do usuário. Falando especificamente de usuários com deficiência, ainda predomina uma abordagem cuja estética ainda não superou um aspecto "hospitalar" e pouco atrativo. Falta cumprir a necessidade por parte do usuário com deficiência de um artefato que não só atenda a suas necessidades físicas, como também estéticas e emocionais. Além disso, mais pesquisas voltadas para a correlação entre o design e o desenvolvimento de produtos para o público do espectro autista são imperativas, já que, como analisado anteriormente, tais artefatos podem contribuir positivamente para uma melhor interação do usuário autista com as outras pessoas para sua melhor inserção na vida em sociedade. Ao possuir a possibilidade de controlar minimante o a própria interação com o ambiente, a pessoa com autismo amplia, também, as próprias capacidades cognitivas.

Após a análise experimental sobre o Squease Vest, foi possível observar que foram levados em consideração, no processo de projetá-lo, princípios básicos do design universal, possivelmente melhor contemplados devido ao seu vínculo com outros princípios, mais profundamente estudados dentro do design emocional. Trata-se de um artefato que, ao contrário de muitos outros também com função assistiva, tem uma estética agradável e valoriza a dimensão psicológica de seus usuários: busca conferir conforto e segurança capazes de aumentar a autonomia dos mesmos, permitindo que realizem de forma otimizada suas tarefas.

A pesquisa, em seu caráter experimental, contribuiu para demonstrar o potencial do estudo do design emocional na avaliação de artefatos inclusivos, sendo encorajado para estudos posteriores.

Por fim, reforça-se a importância de levar em consideração o viés emocional do design, também, ao projetar, tornando seus parâmetros uma poderosa ferramenta para a criação de artefatos que atendam em dimensão mais ampla a necessidade de seus usuários, especialmente se tratando de artefatos inclusivos voltados para usuários com autismo.

\footnotetext{
${ }^{3}$ Disponível em: https://www.squeasewear.com/about/product-features/
} 


\section{Referências}

DUVALL, Julia. (2017). "Bear Hug: The Design and Development of an Active Deep Touch Pressure Garment for Sensory Processing Disorder". MSc in Design, University of Minnesota.

FRANCISCO, Paulo C. M. \& MENEZES, Alexandre M. (2011). “Design Universal, acessibilidade e espaço construído". Construindo, Belo Horizonte, v.3, n.1, p.25-29, 2011.

HEKKERT, Paul. (2006). “Design Aesthetics: Principles of Pleasure in Design”. Psychology Science, Volume 48 (2006), p. 157-172.

HILLNER, Matthias. (2013). "IP, an interesting phenomenon the relevance of patents for the design-led start-up business". Proceedings of the 2013 Tsinghua International Design Management Symposium, p. 370-380.

NAKAYAMA, Gabriela Y. "Desenvolvimento de produtos de moda para pessoas com mobilidade reduzida: ferramenta metodológica pautada na ergonomia". Dissertação (Mestrado) Universidade Federal de Pernambuco. Design, 2016. (Adaptado)

NORMAN, Donald A. (2004) “Emotional Design”. Basic Books, New York, NY. 2004.

OVERBEEKE, Kees C.J. \& WENSVEEN, Stephan S.A.G. (2003). “From Perception to Experience, From Affordables to Irresistibles". DPPI 2003 - Proceedings of the 2003 International Conference on Designing Pleasurable Products and Interfaces.

SILVA, Cátia Sofia Morgado Rafael. (2011). "Design de produto para crianças autistas”. Dissertação (Mestrado) - Universidade Técnica de Lisboa. Faculdade de Arquitectura, 2011.

TONETTO, Leandro Miletto \& COSTA, Filipe. (2011). “Design Emocional: conceitos, abordagens e perspectivas de pesquisa”. Strategic Design Research Journal. 4, p.132-140.

THE CENTER FOR UNIVERSAL DESIGN. “The Principles of Universal Design, Version 2.0”. Raleigh, NC: North Carolina State University, p. 107-108. 1997.

YIN, Robert K. "Estudo de Caso: Planejamento e Métodos". Trad. Daniel Grassi - 2a ed. - Porto Alegre: Bookman, 2001.

\section{Apêndice}

Tabela 1 - Análise Produtos - Design Universal

\begin{tabular}{llll}
\hline & Atende Não atende Não se aplica \\
\hline
\end{tabular}

1. Requisitos norteadores -

Caracterização do artefato

$\begin{array}{ll}\text { 1a. Necessidades mercadológicas } & \mathrm{x} \\ \begin{array}{l}\text { 1b. Necessidades simbólicas } \\ \text { 1c. Autonomia do usuário }\end{array} & \mathrm{x} \\ \begin{array}{l}\text { 1d. Considerações sobre tecnologias assistivas } \\ \text { 1e. Respeito ao ritmo corporal do usuário }\end{array} & \mathrm{x}\end{array}$




\section{Requisitos gerais}

\begin{tabular}{ll} 
2a. Otimização da tarefa primordial & $x$ \\
2b. Facilidade no uso & $x$ \\
2c. Adequação e clareza & $x$ \\
\hline
\end{tabular}

\section{Requisitos dos materiais}

3a. Contato do material com a pele
3b. Conforto térmico
3c. Peso sobre o corpo
3d. Flexibilidade
3e. Segurança e manutenção

\section{Requisitos de uso}

$\begin{array}{ll}\text { 4a. Alcance e mobilidade } & \text { x } \\ \text { 4b. Uso flexível } & x \\ \text { 4c. Ajuste } & x\end{array}$

\section{Requisitos avaliativos}

\begin{tabular}{ll}
\hline 5a. Estético-simbólico & $\times$ \\
5b. Assimilação e facilidade & $\times$ \\
5c. Conforto global & $\times$ \\
\hline
\end{tabular}

\section{Requisitos finais do produto}

$\begin{array}{lc}\text { 6a. Manutenção do produto } & x \\ \text { 6b. Clareza de informações } & x \\ \text { 6c. Otimização processual } & x\end{array}$

Fonte: adaptado de Nakayama, Gabriela Y. "Desenvolvimento de produtos de moda para pessoas com mobilidade reduzida: ferramenta metodológica pautada na ergonomia”. Dissertação (Mestrado) - Universidade Federal de Pernambuco. Design, 2016

Tabela 2 - Estudo de caso - Desenho Universal

Não se Aplicável Muito aplicável
aplica




\section{Uso equitativo}

1a. Provê o mesmo modo de uso para todos: idêntico quando possível ou equivalente quando não

1b. Evita a segregação ou estigma de qualquer usuário

1c. Faz provisões quanto à privacidade, segurança / usuários

1d. Faz o projeto atrativo para todos os usuários

$\mathrm{x}$

\section{Uso flexível}

2a. Provê escolhas de formas de utilização

2b. Permite o acesso e o uso para destros e canhotos

2c. Facilita a precisão e exatidão

2d. Provê adaptação para o ritmo do usuário

$x$

\section{Uso simples e intuitivo}

3a. Elimina complexidades desnecessárias

3b. É consistente com as expectativas e intuição dos usuários

3c. Acomoda uma ampla gama de habilidades linguísticas e literárias

3d. Organiza a informação consistente com sua importância

3e. Proporciona informação efetiva e pontual $x$ durante e depois da realização da tarefa

\section{Informação percebível}

4a. Emprega diferentes mobilidades (verbais, táteis, pictóricas) para redundante apresen-tação da informação essencial

4b. Maximiza a legibilidade da informação essencial

4c. Diferencia elementos de modo que possam ser descritos (torna fácil e dá instruções ou direções)

4d. Provê compatibilidade com uma série de técnicas e dispositivos usados por pessoas com limitações sensoriais 


\section{Tolerância ao erro}

5a. organiza os elementos de modo a evitar perigos $\mathrm{x}$ ou erros: elementos mais usados - mais acessíveis; elementos perigosos - eliminados, isolados ou protegidos

5b. provê advertências quanto a perigos e erros

5c. proporciona elementos de segurança diante do erro

$5 d$. desencoraja a realização de ações involuntárias em tarefas que requerem vigilância

\section{Mínimo esforço físico}

6a. Permite ao usuário manter a posição neutra do corpo

6b. Utiliza uma força operacional razoável

6c. Minimiza ações repetitivas

$\mathrm{X}$

6d. Minimiza a manutenção de esforços físicos

7. Espaços e dimensões adequados para aproximação e uso

7a. Provê uma clara linha de visão para os mais importantes elementos para usuários sentados ou em pé

7b. Permite o alcance dos componentes de forma $x$ confortável para usuários sentados ou em pé

7c. Acomoda variações de manipulação e pega

7d. Prover adequado espaço para o uso de dispositivos de assistência ou ajuda pessoal

Fonte: adaptado de "The Center for Universal Design (1997). The Principles of Universal Design, Version 2.0. Raleigh, NC: North Carolina State University". Conforme os defensores de origem anglo-saxônica do Design Universal, listados em ordem alfabética: Bettye Rose Connell, Mike Jones, Ron Mace, Jim Mueller, Abir Mullick, Elaine Ostroff, Jon Stanford, Ed Steinfeld, Molly Story, Gregg Vanderheiden 